\title{
Debut Politik Muhammad Ibn Abdul Wahhab \& Muhammad Ibn Saud
}

\author{
Ali Yazid Hamdani \\ UIN Sunan Kalijaga Yogyakarta \\ yazidyizaidz1001@gmail.com
}

\begin{abstract}
In the middle of the 18th century to be precise in 1746, the new power of Saudi Arabia was successfully formed and started with two influential people, namely Muhammad Ibn Saud and Muhammad ibn Abdul Wabhab. Through their religious authority, these two figures, through some of their ideas, are obsessed with purifying Islamic law from heretical, khurafat, and superstitions. This study aims to investigate further how Mubammad Ibn Abdul Wabhab's theological thoughts, the social and economic conditions of Saudi Arabia, and their influence in the world of politics, led to the formation of alMamlakah al-'Arabiyyah al-Su'udiyyah? This study uses library-based research, which is by collecting data as well as examining related references used to provide the picture referred to by referring to the writings of Mubammad Ibn Abdul Wabhab as the primary source and other related literatures. With the object of research as a secondary reference source.
\end{abstract}

\section{Keyword: Muhammad Ibn Abdul Wahhab, Muhammad Ibn Saud}

Abstrak. Pada pertengahan abad 18 tepatnya tahun 1746, kekuasaan baru Saudi Arabia berhasil dibentuk dan dimulai dengan dua orang yang berpengaruh yakni Muhammad Ibn Saud dan Muhammad ibn Abdul Wahhab. Melalui otoritas keagamaannya, kedua tokoh ini melalui beberapa gagasan-gagasannya yang terobsesi memurnikan syariat Islam dari perilaku bid'ah, kburafat, dan takhayul. Penelitian ini bertujuan untuk menelisik lebih jauh bagaimana pemikiran teologi Muhammad Ibn Abdul Wahhab, kondisi sosial, ekonomi Arab Saudi, dan pengaruhnya dalam dunia perpolitikan hingga terbentuknya al-Mamlakah al-'Arabiyyah al-Su'udiyyah? Penelitian ini menggunakan riset berbasis pustaka (library-based research), yaitu dengan mengumpulkan data sekaligus meneliti refrensi-refrensi terkait yang digunakan untuk memberikan gambaran yang dimaksud dengan mengacu pada tulisan-tulisan Muhammad Ibn Abdul Wahhab sebagai sumber primer dan literatur-literatur lain yang berkaitan dengan objek penelitian sebagai sumber rujukan sekunder.

\section{Kata Kunci: Muhammad Ibn Abdul Wahhab, Muhammad Ibn Saud PENDAHULUAN}

Islam sejak muncul dan berdirinya telah memberikan pengaruh besar dalam dinamika kehidupan sosial keagamaan secara khusus dan sosial kemasyarakatan pada umumnya. Bukan saja hadir bagaimana seorang hamba 
beribadah atau hubungan pada Allah semata, atau bahkan tentang halal haram saja, namun lebih luas dari itu, termasuk hubungan dengan sesamanya yang meliputi; ekonomi, sosial, budaya, hingga memuat politik. Diakui atau tidak Islam merupakan agama yang kaya akan pemikiran politiknya. Bahkan menurut Harun Nasution menyatakan, persoalan yang pertama-tama muncul dalam sejarah Islam bukanlah persoalan yang berkenan dengan keyakinan (akidah) yang merupakan inti ajaran Islam, melainkan persoalan politik (Nasution, 1985, h. 88).

Pemikiran politik Islam mencakup berbagai dimensi yang dibingkai, mulai dari konsep, etika politik, filsafat politik, hingga hukum dan tata negaranya pun tidak luput dari bahasan. Keragaman pemikiran politik Islam dapat dikatakan bermuara dari hubungan agama dan negara. Jika mau menelisik ke belakang, keduanya memiliki perjalanan sejarah yang cukup panjang. Bermula dari Nabi Muhammad Saw. yang mendirikan komunitas di Madinah yang suku, agama, dan budaya masyarakatnya beragam, sering terjadi pertikaian, bahkan peperangan yang kerap kali terjadi berhasil disatukan dalam satu naungan, yakni komunitas Islam yang pada puncaknya menjadi sebuah negara Madinah dan Rasul sebagai pemimpinnya.

Pada fase kedua dakwah Nabi di Madinah ini, Islam berkembang yang semula sekedar agama menjadi sebuah negara, dari sini pula peran nabi tidak hanya sebagai rasul Allah tapi juga sebagai politisi dan negarawan. Peran ganda ini yang seringkali dijadikan bukti sarjana modern untuk menunjukkan hubungan yang begitu erat antara Islam dan politik (Hitti, 2005, h. 115).

Di semenanjung Arabia dalam perjalanan sejarahnya telah mengalami berbagai perpindahan kekuasaan politik. Adapun kekuasaan yang pernah lahir dan singgah di negeri kelahiran Islam ini adalah kekuasaan Kbulafa ar-Rasyidin, Bani Umayyah, Bani Abbasiyah, dan jauh di tahun selanjutnya tepatnya pada awal abad 16 Turki Usmani memegang kekuasaan bahkan telah dijadikan propinsi-propinsi dari kerajaan Turki Usmani (Yatim, 1999, h. 2). Pada 
pertengahan abad 18 (1746) kekuasaan baru Saudi Arabia berhasil dibentuk dan dimulai. Dengan dilakoni dua sosok berpengaruh Muhammad Ibn Saud yang merupakan kepala kabilah kecil di wilayah Dar'iyyah dan Muhammad ibn Abdul Wahhab dengan otoritas keagamaannya melalui beberapa gagasangagasannya yang terobsesi memurnikan syariat Islam dan mengislamkan kembali umat Islam yang menurutnya sudah tidak lagi Islam lantaran membiaknya perilaku bid'ah, khurafat, dan takhayul yang menurutnya memunggungi Aqidah dan dari apa yang diajarkan Alquran dan Sunnah. Seperti halnya pemujaan terhadap orang-orang suci dan tempat-tempat pemakamannya, menjamurnya praktik tasawuf, dan sebagainya. Hingga pada puncaknya gerakan yang dipelopori Muhammad Ibnu Abdul Wahhab ini dikenal dengan sebutan Wahhabisme.

Kolaborasi antara visi spiritual yang dilakoni Syaikh Muhammad Abdul Wahhab dan ambisi kekuasaan yang dimotori Muhammad Ibn Saud dapat dikatakan sebagai dwi-tunggal yang saling mengisi kekurangan untuk mencapai apa yang menjadi tujuan. Pada puncaknya terbentuklah religi-politis yang berhasil menguasai Mekkah dan Madinah pada tahun 1802. Lalu mendirikan negara dengan nama al-Mamlakah al'Arabiyah al-Su'udiyyah yang selanjutnya dikenal Kerajaan Arab Saudi atau Saudi Arabia dan Wahhabisme pun menjadi gerakan ideologi keagamaannya.

Dari hubungan keduanya yang saling menguntungkan satu sama lain. Muhammad Said Al-Asymawi (2004) mengatakan bahwa Al-Wahhab bisa menanamkan doktrin pemerintahan Tuhan berbasis Wahabi yang diyakininya. Sedangkan Ibn Saud mendapatkan keuntungan politik dari doktrin religio politik yang ditawarkan oleh al-Wahhab. Untuk memperkuat posisinya di hadapan penguasa Arabia itu, al-Wahhab menawarkan konsep ketaatan mutlak masyarakat pada penguasa, menolak musyawarah, dan melarang mereka keluar dari suatu negara (Wijaya, 2018, h. 40-41). Tawaran al-Wahhab tersebut turut menjadikan Arab Saudi menganut sistem 
pemerintahan Monarki absolut dengan corak keberagamaan yang ultrakonservatif. Dengan sistem pemerintahan tersebut tidak ada proses pemilihan langsung dalam pergantian penguasa kerajaan Saudi. Kekuasaan sang raja diwariskan secara turun temurun melalui trah keluarga Saud. Sistem ini tentu menjadi berkah tersendiri bagi keluarga kerajaan (Mas'odi, 2020, h. 54).

Dari pemaparan di muka, penelitian ini bertujuan untuk menelisik lebih jauh bagaimana pemikiran teologi Muhammad Ibn Abdul Wahhab, kondisi sosial, ekonomi Arab Saudi, pengaruhnya dalam catur perpolitikan hingga terbentuknya al-Mamlakah al-'Arabiyyah al-Su'udiyyah? Demi tercapainya hal tersebut, penelitian ini menggunakan riset berbasis pustaka (library-based research), yaitu dengan mengumpulkan data sekaligus meneliti referensireferensi terkait yang digunakan untuk memberikan gambaran yang dimaksud dengan mengacu pada tulisan-tulisan Muhammad Ibn Abdul Wahhab sebagai sumber primer dan literatur-literatur lain yang berkaitan dengan objek penelitian sebagai sumber rujukan sekunder.

\section{HASIL DAN PEMBAHASAN}

\section{Konsep Dasar Ajaran Wahabi}

Ketika membahas Wahhabisme tentu tidak akan lepas dari pendirinya Muhammad Ibn Abdul Wahhab yang diketahui hidup pada tahun 1115-1206 H (1703-1792) Seorang tokoh terkemuka yang lahir di daerah dusun Ujainah, daerah Saudi Arabia sebelah Timur. Ekspansi Wahabi yang begitu meluas tidak dapat dipisahkan dari legitimasi keagamaan dari pemikiran teologi pendirinya.

Sebelum menuju belantara pemikiran Muhammad Ibn Abdul Wahhab ini, akan lebih baik mengenal dan mengetahui terlebih dahulu kaidah berfikir dan cara berargumentasinya. Hal itu dalam kitabnya Arb'u Qawa'id dan al-Qawa'id al-Arba'a. Nur Khalik Ridwan dalam bukunya Sejarah Lengkap Wahhabi (2020) menyebut kitab tersebut sebagai petunjuk dasar untuk 
mengetahui logika berfikir Muhammad ibn Abdul Wahhab dalam pengambilan hukum (ber-istidlal) (Ridwan, 2020, h. 66).

Berikut empat dasar kaidah berfikir ala Muhammad Ibn Abdul Wahhab dalam Arba'u Qawa'id: Pertama, Haram membicarakan Allah SWT. Tanpa memiliki ilmu. Kedua, setiap sesuatu yang pembuat syariat diam (tidak membicarakannya) maka dimaafkan, seseorang tidak boleh mengharamkannya, mewajibkannya, menganjurkannya, atau memakruhkannya. Ketiga, meninggalkan dalil yang sudah jelas (qath'i) dan mengambil dalil dari lafaz mutasyabihat (lafaz yang mengandung kesamaran dan multi-makna) ialah jalan sesat, seperti kelompok Rafidhah dan Khawarij. Setiap muslim wajib mengikuti yang mubkam (yang sudah jelas), dan jika mengetahui makna yang mutasyabihat (yang samar) dan menemukannya tidaklah boleh menyelisihi yang mubkam, sebaliknya harus sepakat dengan yang mubkam. Dan, jika tidak, maka wajib baginya mengikuti ar-rasikbun. Keempat, Nabi Muhammad Saw menuturkan, "Hal yang halal itu sudah jelas, yang haram itu juga jelas, di antara keduanya ialah perkara-perkara mutasyabihat (biasa juga disebut Musytabihat, yang dalam tradisi ulum alqur'an sebagian kata itu berarti kata-kata yang artinya samar)." Barang siapa yang tidak mempercayai kaidah ini, dan berkeinginan membicarakan masalah secara fashilin (terperinci) maka orang itu sesat dan menyesatkan (Ridwan, 2020, h. 66).

Sebagai pijakan dari kaidah tersebut, ia menitik-tekankan pada persoalan praktik jahiliah yang harus dihancurkan. Hal ini tertuang dalam kitabnya menyebutkan sebagai masalah keenam dalam Masail al-Jabiliab;

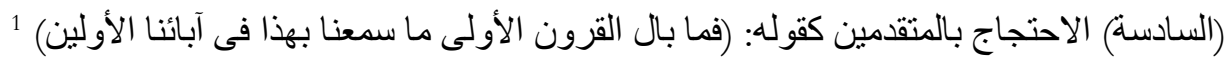

\footnotetext{
${ }^{1}$ Yang ke-6 dari persoalan jahiliyah ialah berhujah dengan mutaqaddimin, dalilnya ialah surah Thaha ayat 51 dan al-Ahqaf ayat 26. Lihat, Muhammad Ibn Abdul Wahhab, Muallafat, hal 337
} 
Di kitab yang berbeda Al-Qawa'id al-Arba' menjelaskan kaidah berpikirnya sebagaimana yang diatas sebagai pelengkap kaidah dari yang empat tadi. Pertama, ketahuilah bahwa orang-orang kafir yang diperangi oleh Rasulullah Saw. Mengakui bahwa Allah SWT. Ialah pencipta, tetapi itu tidak memasukkan mereka dalam Islam, dalilnya ialah surat Yunus ayat 31. Kedua, mereka (orang kafir) mengatakan bahwa mereka tidak berdoa dan tidak bertawajjah kepada mereka (yang dijadikan perantara) kecuali untuk mendekatkan diri kepada Allah SWT., ialah surat az-Zumar ayat 3 dan dalil untuk kepentingan syafaat ialah surat Yunus ayat 8. Ketiga, Nabi Muhammad Saw. Menjelaskan bahwasanya manusia itu berbeda-beda didalam peribadatan,di antara mereka ada yang menyembah malaikat, ada yang menyembah nabinabi dan orang sholih, ada yang menyembah batu-batu, pohon, matahari, dan bulan. Rasulullah membunuh mereka, dan tidak dibedakan di antara mereka.

Dalilnya ialah surat al-Anfaal ayat 39, Fushshilat ayat 37, Ali 'imron ayat 80 , al-Ma'idah ayat 116 , al-Israa' ayat 57, an-Najm ayat 19-20, dan hadits dari Abi Waqid al-Laitsi. Keempat, orang-orang musyrik pada zaman kita ini lebih besar kesyirikan-nya dari pada orang terdahulu, karena orang-orang terdahulu melakukan kesyirikan pada waktu kuat, tetapi mereka ikhlas ketika lemah. Sementara, kesyirikan orang-orang musyrik pada zaman kita ini langgeng, terjadi pada waktu lemah dan kuat (fi rakha'wa syiddab). Dalil dari kaidah ini ialah surat al-Ankabuut ayat 65 (Ridwan, 2020, h. 68).

Persoalan kaidah yang berkaitan dengan orang musyrik ini, diperkuat dalam kitabnya Kasyfu as-Syubhat (Ridwan, 2020, h. 130).

فمن فهم هذهالمسألة التى وضحه الله فى كتابه،وهي أن المشركين الذين قاتلهم رسول الله صلى الله عليه وسلم يدعون الله ويدعون غيره فى الرخاء، وأما فى الضراء والثدة فلا يدعون إلا الله

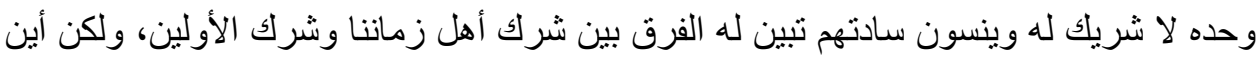

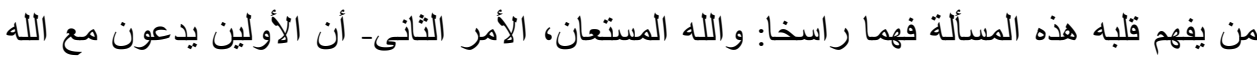

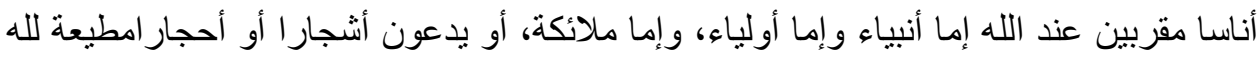

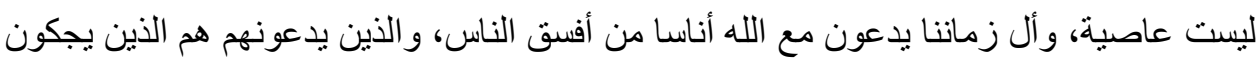




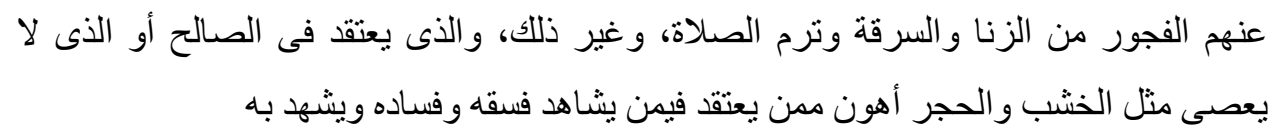

Empat kaidah ini berpikir yang disebutkan terakhir bahkan dikuatkan lagi dalam Kitab Al-Wajibat dengan menyebutkan: "Kaidah agama dua perkara, yaitu: 1) perintah beribadah kepada Allah saja dan tidak menyekutukannya serta takfir atau dihukum kafir bagi yang meninggalkannya; dan 2) peringatan bahwa syirik dalam ibadah terhadap selain Allah.... dan takfir bagi yang melakukannya.

Dari kaidah tersebut sangat mempengaruhi kemudian kerangka gagasan-gagasan teologinya. Pertama, mengenai Takfir, dalam hal ini penjelasan mengenai takfir sangat erat kaitannya dengan gagasannya mengenai tauhid, thaghut, dan syirik.

Tauhid yang benar bagi Muhammad Abdul Wahhab merupakan Mengesakan Allah dalam beribadah (Wahhab, 2004, h. 23). Konsep tauhid dan takfirnya ini dapat ditemukan dalam beberapa karyanya; Kasyfu as-Syubhat, Ma'na at-Thaguth, Ushul ats-Tsalatsah, Ushul Sittah, Kitab at-Taubid alladzi Huwa Haqqubu'ala al-'Abid.

Lalu Muhammad Ibn Abdul Wahhab memberikan klasifikasi tauhidnya menjadi tiga; pertama, Taubid Rububiyah, yang diakui oleh orangorang kafir Makkah, tetapi Raasulullah SAW membunuh mereka, dan itu tidak menyebabkan mereka masuk dalam kategori muslim, sehingga darah dan harta mereka halal. Kedua, Taubid Ulubiyah, yaitu mengesakan Allah dengan perbuatan-perbuatan manusia, seperti dalam doa, raja', khauf, nahr, tawakkal, dan sebagainya. Dan ketiga, tauhid dzat, asma, dan sifat (Wahhab, n.d., h. 6).

Harun Nasution juga menyatakan dalam bukunya Pembaharuan dalam Islam (1975) Muhammad Ibn Abdul Wahhab perhatian pada masalah berikut; 1) yang boleh dan harus disembah hanyalah Tuhan, dan orang-orang yang menyembah selain Tuhan telah menjadi musyrik, dan boleh dibunuh; 2) 
kebanyakan orang Islam bukan lagi penganut faham tauhid yang sebenarnya karena mereka meminta pertolongan bukan lagi kepada Tuhan, tetapi kepada para syaikh atau wali dan dari kekuatan gaib. Orang Islam demikian juga telah menjadi musyrik; 3) menyebut nama nabi, syaikh atau malaikat sebagai perantara dalam doa juga merupakan syirik; 4) meminta syafaat selain kepada Tuhan adalah juga syirik; 5) bernazar kepada selain Tuhan juga syirik; 6) memperoleh pengetahuan selain dari Alquran, hadis, dan kias (analogi) merupakan kekufuran; 7) tidak percaya kepada qada dan qadar Tuhan juga merupakan kekufuran; dan 8) penafsiran al-qur'an dengan takwil (interpretasi bebas) adalah kufur (Nasution, 1975, h. 25). Siapapun yang memunggungi taudih sebagaimana dikonsepsikan maka orang tersebut dapat dikatakan sesat menurut ajaran ini.

Yang semula dari doktrin tauhid dengan konsep pembaharuan dan ambisi pemurniannya untuk kembali kepada Alquran dan hadits, namun sayang, akhirnya jatuh pada ranah politik (Mangasing, 2008, h. 327). Dari konsep ini menjadi titik tolak ekspansi ajarannya menyeluruh santero Arabia bahkan hingga mendunia. Menurut Olivier Roy dalam bukunya Globalized Islam: The Search for a New Ummah (2004), sebagaimana dikutip Ihsan AliFauzan dalam pengantar buku Wahhabisme karya Hamid Algar (2011), bahwa Wahhabisme sebagai cikal-bakal model keberagamaan Islam yang disebutnya -neo-fundamentall, yang dicirikan oleh pandangan bahwa merekalah satu-satunya kelompok Muslim yang benar dan tidak mungkin ada di luar aliran mereka (Algar, 2011, h. 14).

\section{PENUTUP}

Dari pemaparan di atas, debut panjang Muhammad Ibn Saud dan Muhammad Ibn Abdul Wahhab untuk memperluas kekuasaan dan ide gagasannya mengalami proses yang begitu panjang hingga akhirnya tersebar dan mendunia. Wahabisme digunakan oleh Ibn Saud untuk melegitimasi gerakan politiknya untuk menguasai suku-suku Arab. Dengan ajaran Wahabi 
ini sebagai patron gerakan politik Ibn Saud melahirkan sebuah kebijakan yang keras dalam merespon gesekan ataupun perlawanan yang muncul dari bawah. Sebagaimana ajaran Wahabi, Ibn Saud menghalalkan darah pihak-pihak lain yang tidak sepemikiran dengan kebijakan yang dikeluarkan pihak keluarga Saud.

\section{DAFTAR REFERENSI}

Algar, H. (2011). Wahabisme: Sebuah Tinjanan Kritis. Democracy Project.

Hitti, P. K. (2005). History of the Arabs: Rujukan Induk dan Paling otoritatif tentang Sejarah Peradaban Islam. PT. Serambi Ilmu Semesta.

Mangasing, M. (2008). Muhammad Ibn Abdul Wahhab dan Gerakan

Wahhabi. Jurnal Hunafa, 5(3), 327.

Mas'odi. (2020). Wahhabisme vis-a-vis Reformasi Arab: MBS, Agensi,

Moderasi, dan Diversifikasi Ekonomi. Jurnal Al-Irfan, 3(1), 54.

Nasution, H. (1975). Pembaharuan dalam Islam. Bulan Bintang.

Nasution, H. (1985). Islam Ditinjau dari Berbagai Aspeknya (I). UI Press.

Ridwan, N. K. (2020). Sejarah Lengkap Wababi: Perjalanan Panjang Sejarah,

Doktrin, Amaliyah, dan Pergulatannya. Ircisod.

Wahhab, M. I. A. (n.d.). Al-Wajibat.

Wahhab, M. I. A. (2004). Kasyfu as-Syubhat dalam Mubammad Ibn Shalil

Utsaimin, Syarb Kasyfu asy-Syubhat. Media Hidayah.

Wijaya, A. (2018). Dari Membela Tuban ke Membela Manusia: Kritike atas Nalar Agamaisasi Kekerasan. Penerbit Mizan.

Yatim, B. (1999). Sejarah Sosial Keagamaan Tanah Suci Hijaz. (Mekekah dan Madinah) 1800-1925. Logos Wacana Ilmu. 